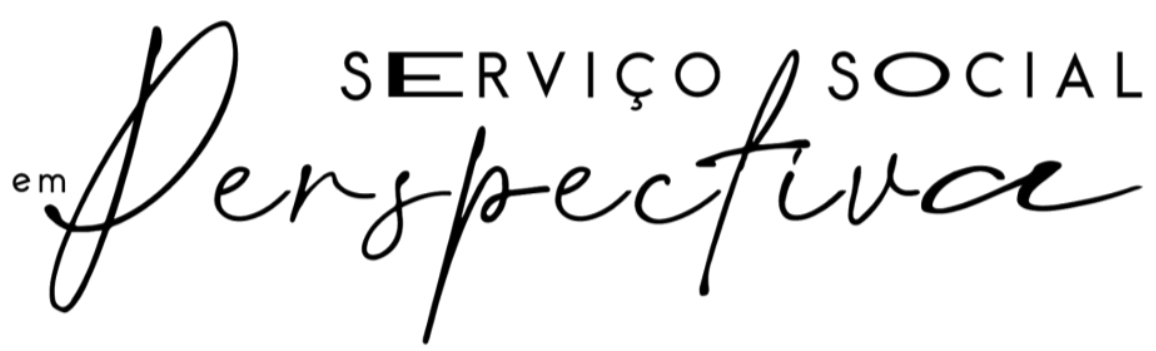

Montes Claros (MG), volume 5, número 2, jul./dez. 2021. I ISSN 2527-1849

\title{
FORMAÇÃO PROFISSIONAL EM SERVIÇO SOCIAL E POLÍTICA DE EDUCAÇÃO SUPERIOR NO ÂMBITO DAS IES DO PROCAD-AMAZÔNIA: ELEMENTOS PARA O DEBATE
}

\section{PROFESSIONAL TRAINING IN SOCIAL WORK AND HIGHER EDUCATION POLICY IN THE FRAMEWORK OF PROCAD-AMAZÔNIA HEI: ELEMENTS FOR THE DISCUSSION}

\author{
Vera Lúcia Batista Gomes 1 \\ Sara Daltro Tavares Paiva ${ }^{2}$ \\ Karina Camille Marques Cezar ${ }^{3}$
}

\begin{abstract}
Resumo: Este artigo teve o propósito de analisar a formação profissional de assistentes sociais e as comutações da politica de educação superior. Foi baseado em análises sobre a produção de conhecimento de dissertações e teses sobre formação profissional e politica de educação. desenvolvidas nos Programas de Pós-Graduação em Serviço Social das IES que integram o PROCAD/Amazônia (2018). A luz da teoria marxista, os resultados apontam que tanto nas universidades públicas federais quanto nas privadas, devido ao sucateamento e a precarização do ensino superior. decorrentes das medidas ultraneoliberais expressas na restrição orçamentária para a politica de educação superior, a formação em Serviço Social vem sendo ameaçada, tornando-se imperiosas as lutas coletivas para o acesso aos direitos da classe trabalhadora.
\end{abstract}

Palavras-chaves: Formação Profissional. Serviço Social. Política de Educação

Abstract: This article aimed to analyze the professional training of social workers and the changes in higher education policy. It was based on analyzes of the production of knowledge

\footnotetext{
'Assistente social graduada em Serviço Social pela Universidade Federal do Pará, Mestrado Em Serviço Social - Universidade Federal do Pará e doutorado em Sociologia do Trabalho - Université de Picardie Jules Vernes: Docente da faculdade de Serviço Social da Universidade Federal do Pará - UFPA e do Programa de Pós-graduação em Serviço Social - PPGSS/UFPA; Coordenadora/Pesquisadora do grupo de pesquisa Trabalho, Estado e Sociedade na Amazônia - GEPTESA. https://orcid.org/0000-002-8146-5082 E-mail: Veragomesbelem@hotmail.com:

2 Assistente Social formada pela Universidade Federal do Pará - UFPA; Mestranda do Programa de Pósgraduação em Serviço Social - PPGSS/UFPA; Pesquisadora do grupo de estudos e pesquisa Trabalho, Estado e Sociedade na Amazônia - GEPTESA. https://orcidorg/0000-0001-6294-3459 E-mail: saradaltro223@gmail.com

3 Assistente Social formada pela Universidade Federal do Pará - UFPA e Especialista em Gestão e Planejamento de Políticas Públicas em Serviço Social pela Escola Superior da Amazônia - ESAMAZ; Mestranda do Programa de Pós-graduação em Serviço Social - PPGSS/UFPA; Pesquisadora do Grupo de Estudos, Pesquisa e Extensão em Serviço Social e Politica Social na Amazônia - GEPSS; https://orcid.org/0000-0002-6591-6189 E-mail karinamarquesas@hotmail.com
}

Artigo submetido em: 12 de abril de 2021 .

Artigo aceito em: 21 de maio de 2021.

p. 34-56. DOI: https://doi.org/10.46551/rssp202118 
GOMES, V. L. B; PAIVA, S. D. T; CEZAR, K. C. M.

Formação profissional em Serviço Social e política de educação superior no âmbito das IES do PROCADAmazônia: elementos para o debate

from dissertations and theses on professional training and education policy, developed in the Postgraduate Programs in Social Work of the HEls that make up PROCAD/Amazônia (2018). In the light of Marxist theory, the results show that both in federal public and private universities, due to the scrapping and precariousness of higher education, resulting from ultra-neoliberal measures expressed in the budget constraint for higher education policy. training in Social Work has been threatened, and collective struggles for access to the rights of the working class are becoming imperative.

Keywords: Professional qualification. Social service. Education Policy

INTRODUÇÃO

Para compreender a formação profissional, em Serviço Social, no Brasil, precisase ressaltar sua concepção enquanto uma especialização do trabalho coletivo, inserida na divisão sócio técnica do trabalho. Sua trajetória histórica é marcada pelas determinações econômicas, políticas e sociais, na fase madura do capital, momento em que a classe trabalhadora passou a reivindicar os seus direitos e melhorias de condições de trabalho, exigindo respostas do Estado, para mediar as contradições sociais decorrente da relação capital x trabalho. Desta forma, o lals assistentes sociais foram chamadolals para intervir nas expressões da questão social via políticas públicas e sociais, o que exigiu uma formação profissional capaz de dar respostas às demandas emergentes.

Nesta perspectiva, responder às requisições postas pelo empregador a força de trabalho do (a)s assistentes sociais, demandou, inicialmente, um processo de formação que respondesse às demandas do Estado burguês e das organizações capitalistas, na intermediação, junto a classe trabalhadora, direcionada para a manutenção do sistema e dos ganhos dos capitalistas. Desse modo, o processo formativo, em Serviço Social, inicialmente, teve por base o conhecimento teórico metodológico das ciências sociais de cunho positivista e funcionalista, para atuar junto as expressões da questão social, por meio de práticas psicologizantes voltadas para a integração do mesmo na sociedade. pois atribuíam ao individuo a responsabilidade pela sua "situação-problema". Em concordância com o projeto societário burguês, esta formação profissional era orientada pelas premissas de naturalização das relações contraditórias e excludentes.

Assim, tanto o surgimento da profissão quanto a formação profissional de assistentes sociais, no contexto sócio-político e econômico brasileiro, se deu no âmbito da operacionalização das políticas sociais do Estado, marcadamente cunhada por interlocuções com as perspectivas positivistas/funcionalistas e com a filosofia Serviço Social em Perspectiva, Montes Claros (MG), volume 5. número 2. jul./dez. 2021. ISSN 2527-1849 
GOMES, V. L. B; PAIVA, S. D. T; CEZAR, K. C. M.

Formação profissional em Serviço Social e política de educação superior no âmbito das IES do PROCADAmazônia: elementos para o debate

cristã/católica, considerando que as primeiras escolas de Serviço Social, no país, se vinculavam a instituição religiosa.

Com efeito, as ações educativas e doutrinárias de prevenção, readequação e reajuste ao convívio "normal" da sociedade (IAMAMOTO; CARVALHO, 2014), desempenhadas por esses profissionais, incidem, principalmente, no trato com mulheres, crianças e as famílias proletárias. No periodo da ditadura militar ocorrida, no país, foram implementadas modificações na organização e na estrutura da política educacional que repercutiram na formação profissional em Serviço Social, constituindo-se, portanto, como um demarcador imprescindivel para as mudanças endógenas à profissão.

Contudo, no III Congresso Brasileiro de Assistentes Sociais (III CBAS/79), conhecido como Congresso da Virada, organizado pela, então, ABESS foram criadas as bases para - debate sobre os novos para a formação profissional em Serviço Social e a profissão passa a ser "pensada como um fenômeno histórico, sendo condicionada pelo movimento contraditório entre as demandas que são criadas pela sociedade e as respostas elaboradas pela profissão" (BRAVO, RAIZER, LEMOS e ELPÍDIO, 2019, p.72). Com efeito, a formação profissional passou a exigir um rigoroso suporte teórico metodológico necessário à reconstrução do exercício profissional, preparação para a investigação científica e a produção teórica sobre as expressões da questão social no campo de atuação.

Assim, em 1996, a ABESS aprovou Diretrizes Curriculares que definem os pressupostos, princípios e diretrizes para a formação profissional, propondo um anova lógica curricular e a organização dos conhecimentos, em três núcleos: núcleo de fundamentos teórico-metodológicos da vida social: núcleo de fundamentos da formação sócio-histórica da sociedade brasileira: e o núcleo de fundamentos do trabalho profissional (ABEPSS, 1996). Se por um lado, as propostas das Diretrizes Curriculares expressam um avanço na qualidade do processo de formação profissional em Serviço Social, por outro, afetam, frontalmente, a política nacional de Educação brasileira devido a precarização de ensino nas universidades públicas federais e a tendência a expansão dos oligopólios da educação produz um endividamento da classe trabalhadora, a exploração desmedida do trabalho docente, a dificuldade na realização de pesquisa e extensão e a precarização dos vínculos e condições de trabalho. 
GOMES, V. L. B; PAIVA, S. D. T; CEZAR, K. C. M.

Formação profissional em Serviço Social e política de educação superior no âmbito das IES do PROCADAmazônia: elementos para o debate

Essas considerações suscitaram o interesse em aprofundar as análises sobre o tema, sendo assim, este artigo objetiva pesquisar a formação profissional no contexto da politica de educação no Brasil, com ênfase para as instituições formativas que compõem o PROCAD-AMAZÔNIA. Vislumbra-se, ainda, identificar se as Diretrizes Curriculares da ABEPSS estão sendo seguidas pelos cursos de graduação em Serviço Social, o que pode se constituir um indicador sobre a formação profissional, nessas IES.

A sua elaboração teve por base as inferências sobre a produção de conhecimento em dissertações e teses nos sites dos Programas de Pós-Graduação em Serviço Social das Instituições de Ensino Superior (IES) que participam do Programa de Cooperação Acadêmica - PROCAD4/Amazônia (2018), quais sejam: Universidade Federal do Amazonas (UFAM), Universidade Federal do Pará (UFPA) e Pontificia Universidade Católica (PUC) Rio Grande do Sul. Assim, orientou-se a pesquisa para a construção do estado da arte referente às palavras-chaves "educação superior" e "formação profissional", em Serviço Social, no periodo de 2015 a 2020.

artigo foi estruturado da seguinte forma: a primeira parte trata destas notas introdutórias; a segunda se reporta a uma breve discussão sobre a política de educação superior na contemporaneidade e os seus desdobramentos na formação profissional, em Serviço Social; a terceira apresenta os resultados da pesquisa para a construção do estado da arte e, por fim, as conclusões preliminares.

\section{A FORMAÇÃO PROFISSIONAL DO(A) ASSISTENTE SOCIAL E POLITICA DE EDUCAÇÃO SUPERIOR NO BRASIL}

Sobre o processo de formação profissional, em Serviço Social na sociedade contemporânea, considera-se pontuar, ainda que de forma sucinta, a política de educação, no Brasil, nos marcos da crise do capitalismo hordeniente, consequentemente, as suas reverberações sobre a mesma. Em uma breve exposição sobre o sistema educacional,

\footnotetext{
${ }^{4} \mathrm{~A}$ escolha para a análise das produções no âmbito do referido PROCAD, se deu pela participação das autoras deste artigo, no mencionado programa de cooperação acadêmica, objetivando ampliar e consolidar a reflexão teórico-metodológica sobre a formação e o trabalho do assistente social, visando elucidar as aproximações e particularidades entre dois estados da região amazônica (Amazonas e Pará) e de um estado do Sul do Brasil (Rio Grande do Sull, através de cooperação interinstitucional entre os referidos Programas.
} 
GOMES, V. L. B; PAIVA, S. D. T; CEZAR, K. C. M.

Formação profissional em Serviço Social e politica de educação superior no âmbito das IES do PROCADAmazônia: elementos para o debate

no período da ditadura militar, no Brasil, Netto (2011) afirma que ocorreu uma "mudança qualitativa e estrutural, no trato da educação por parte da autocracia burguesa - e que este giro ocorre entre 1968 e 1969" (p.54). Essa modificação se deu em dois distintos momentos. Nos primeiros anos do governo militar, entre 1964-1968, tem-se, como estratégia de controle assumida, as investidas de repressão e destruição das estruturas democráticas de organização discente, além da intimidação do corpo docente e a repreensão das instituições e movimentos populares que se posicionavam contra a estrutura de governo.

Posteriormente, sucedeu-se o momento de refuncionalização das táticas antes utilizadas, quando o governo militar enceta inferências, diretamente, sobre o modelo educacional que passava por um intenso processo de degradação dos alicerces democráticos, congruentes com a centralidade do modelo econômico e as orientações dos organismos internacionais e suas diretrizes para a educação nos países ditos 'em desenvolvimento'. Desta forma, foi estabelecido uma compatibilidade funcionaloperativa entre a política educacional e o conjunto das políticas sociais na ditadura (NETTO, 2011). Em virtude da intensa opressão aos movimentos operários e sindicais, o movimento estudantil desponta como principal ponto de contestação do regime militarista.

Com efeito, "[...] o que preocupa às instancias mais altas do poder é o efeito catalizador da mobilização nas escolas" (NETTO, 2011, p.57): "Assim, o potencial catalizador do movimento estudantil no seio do bloco antiditatorial, explicitado notadamente no curso de 1967 e 1968, que colocou, para o regime autocrático burguês, a questão educacional como prioritária" (lbidem, p. 57).

De forma lacônica, destaca-se desse processo de refuncionalização da política educacional, o contato preliminar do Serviço Social com os debates acadêmicos e com as/os autoras/es de referência nas Ciências Sociais. Assim, no decurso das mobilizações das/os estudantes, da sociedade civil e das/os trabalhadoras/es organizadas/os, houve uma aproximação do Serviço Social com a base da esquerda brasileira, as quais possibilitaram os primeiros contatos com o pensamento marxista, ainda de que forma fragmentada. 
GOMES, V. L. B; PAIVA, S. D. T; CEZAR, K. C. M.

Formação profissional em Serviço Social e política de educação superior no âmbito das IES do PROCADAmazônia: elementos para o debate

Ressalta-se ainda, que a referida refuncionalização da política educacional introduziu no ensino superior a lógica empresarial, elevando a vida acadêmica a um nível de burocratização, nunca antes visto e, por efeito, uma racionalização segmentar que derivou em uma irracionalidade global (NETTO, 2011). As investidas do regime autocrático na politica educacional não sucumbiram às resistências democráticas nos espaços acadêmicos e da sociedade civil, ainda que, as reuniões e encontros fossem restritos. Contudo, é creditado à refuncionalização do espaço universitário, a neutralização e o esvaziamento universitário, conformando-o enquanto ensino superior asséptico, apto a reproduzir profissionais qualificados para efetivação da racionalidade formal-abstrata.

Evidencia-se que, as investidas no âmbito da política educacional, implicaram na abertura significativa da mercantilização do ensino superior, em conformação com as determinações internacionais. Essas mudanças irão em longo prazo, reverberar em projetos de governo conformados com a execução das determinações hegemônicas dos monopólios para a educação, em busca da efetivação de uma formação instrumentaloperativa.

As inflexões desse cenário, no Serviço Social, reforçavam as práticas tradicionais avessas ao processo de amadurecimento teórico-metodológico e prático do Serviço Social. Desta forma, o mercado de trabalho para os assistentes sociais exigia um perfil de trabalhador (a) que operacionalizasse as normas, fluxos, rotina institucional e finalidades compativeis com a racionalidade formal-abstrata. Sendo assim, a formação profissional em Serviço Social, deveria atender aos critérios burocrático-administrativos estabelecidos a uma prática organizacional.

Desta maneira, o currículo geral para formação de assistentes sociais, elaborado na década de 1970, pelo Conselho Federal de Educação, reforça o caráter tecnicista, dividindo-se em dois ciclos, a dizer: básico e profissional. Ao básico, coube as disciplinas de Sociologia, Psicologia, Economia, Direito e Legislação Social e Teoria do Serviço Social. Já o ciclo profissional, abrangeu as disciplinas de Política Social. Método do Serviço Social referente a caso, grupo e comunidade e, por fim, Ética Profissional. Todavia, esta proposta curricular emerge fadada ao fracasso por não refletir os debates que viabilizariam a renovação do Serviço Social (ABREU, 2016). 
GOMES, V. L. B; PAIVA, S. D. T; CEZAR, K. C. M.

Formação profissional em Serviço Social e política de educação superior no âmbito das IES do PROCADAmazônia: elementos para o debate

Nesta esteira, Abreu (2016) aponta dois momentos emblemáticos na história da transformação do direcionamento teórico-político e prático-interventiva no Serviço Social, a dizer: A conquista hegemônica do novo projeto ético-politico profissional, por meio da recusa, pelas profissionais da base crítica, ao conservadorismo, no III Congresso Brasileiro de Assistentes Sociais (III CBAS/79), conhecido como Congresso da Virada, organizado pela então ABESS; e a construção do currículo mínimo de 1982, organizado pelo Conselho Federal de Educação (CFE), acompanhado, diretamente, pela ABESS5.

O projeto profissional de intenção de ruptura se traduz no Currículo de 1982 aprovado na Convenção da ABESS, em 1979, com o envolvimento das unidades de ensino e referendado pelo Conselho Nacional de Educação (CNE) como currículo mínimo pelo Parecer 412-82. Todavia, ainda permanecem resquícios do Serviço Social tradicional no Currículo de 1982, cujas ambiguidades sugeriram modificações para poder avançar na concepção de profissão, no processo de produção e reprodução das relações sociais, as quais foram superadas nas Diretrizes Curriculares de 1996. (ABRAMIDES, 2019, p.55).

Pelo exposto, reconhece-se a importância e a relevância da elaboração do currículo de 1982 como instrumento legal que representava as mudanças que efervesciam na profissão, naquele momento histórico. Destarte, o processo de revisão curricular, posterior, não se restringiu ao aperfeiçoamento do currículo precedente. Aspirava-se um avanço nos debates sobre as novas questões que emergiam, para o Serviço Social e ao conjunto da sociedade, na conjuntura própria do periodo autocrático, propiciando uma transformação drástica endógena da profissão, refletida no amadurecimento das bases teóricas, técnicas e política de construção de uma prática interventiva (IAMAMOTO, 2015).

Destaca-se como uma das pretensões das diretrizes curriculares, o rompimento com a errônea compreensão de uma dicotomia entre teoria/prática, incorrido ao debate do materialismo histórico-dialético e a flexibilidade, descentralização e pluralismo no ensino em Serviço Social. Ademais, emergem questões concernentes a esse processo, tais como: a vinculação do projeto profissional ao projeto societário, além da superação da concepção do Serviço Social como prática profissional, para a concepção como

\footnotetext{
5 A, então, ABESS estabeleceu como principal estratégia de construção desse currículo a realização de uma pesquisa entre 1983/1985 que versava sobre "Formação profissional do assistente social no Brasil: determinantes históricos e perspectivas", visando garantir a unidade dos diversos processos de elaboração de currículos plenos nos mais distintos cursos de Serviço Social, no território nacional. O objetivo desse movimento era garantir os interesses coletivos das classes subalternas (ABREU, 2016; ABRAMIDES, 2019)
} 
GOMES, V. L. B; PAIVA, S. D. T; CEZAR, K. C. M.

Formação profissional em Serviço Social e politica de educação superior no âmbito das IES do PROCADAmazônia: elementos para o debate

trabalho, entre outros. A contribuição desses pressupostos nas referidas diretrizes, reflete o fortalecimento de uma perspectiva emancipatória assumida no projeto pedagógico de formação profissional, em Serviço Social.

Sendo assim, a construção dos projetos pedagógicos dos cursos de Serviço Social deve seguir as Diretrizes Curriculares aprovadas, em 1996, e representa um processo de debate coletivo do corpo acadêmico, da base dos assistentes sociais, das entidades representativas da profissão e do coletivo de estudantes de Serviço Social, sob a coordenação da ABEPSS. O novo currículo irá manter o debate crítico e avança, significativamente, na superação da fragmentação dos conteúdos desenvolvidos nas áreas de conhecimento, visando uma compreensão da totalidade histórica dos processos humanos sociais.

Essa proposta assume as dimensões interventivas e investigativas, enquanto princípios e condições centrais na formação de novos profissionais assim como da própria relação entre as dimensões teórico/práticas. Em vista disso, é necessário um conjunto de conhecimentos indissociáveis que são traduzidos em três núcleos de fundamentação, a dizer: núcleo de fundamentos teórico-metodológicos da vida sociali núcleo de fundamentos da formação sócio-histórica da sociedade brasileira; e o núcleo de fundamentos do trabalho profissional (ABEPSS, 1996).

Esse conjunto de conhecimento e de principios implicam na capacitação teóricometodológica, ético-política e técnico-operativa, as quais auxiliam na apreensão das demandas próprias da realidade cotidiana, enquanto expressões da questão social. Estas emergem para o Serviço Social, através de demandas para o trabalho profissional, nos distintos espaços profissionais, e exigem deste profissional, respostas de enfrentamento as tensões geradas pelo agravamento do tensionamento da relação capital $x$ trabalho.

A proposta das Diretrizes Curriculares (1996) foi apresentada ao Ministério da Educação (MEC), em 1997, sendo submetida à aprovação do Conselho Nacional de Educação (CNE) e, somente, aprovada em 2002. Salienta-se que a Lei de Diretrizes e Bases (LDB) aprovada em 1996, influenciou, diretamente, na adequação das Diretrizes Curriculares (1996) ao documento aprovado pelo MEC, em 2002.

Assim, a proposta original das mencionadas Diretrizes, ao ser submetida ao MEC, sofreu um esvaziamento do direcionamento crítico, ocasionando um reducionismo 
GOMES, V. L. B; PAIVA, S. D. T; CEZAR, K. C. M.

Formação profissional em Serviço Social e política de educação superior no âmbito das IES do PROCADAmazônia: elementos para o debate

teórico-metodológico, desvio ético-político e uma valorização da dimensão do ensino teórico-metodológico, descolando esta última das demais dimensões constitutivas da triade. "Há ainda o agravante de [...] uma pequena parcela dos cursos existentes estaria comprometida com a construção coletiva da formação coordenada por esta entidade" (ABREU, 2016, p.254).

A operacionalização das Diretrizes Curriculares da formação profissional, em Serviço Social, encontra-se ameaçada, também, pelo avanço do projeto burguês, na contemporaneidade, que sob a hegemonia do capital financeiro tem conduzido os Estados, a imprimirem novos rumos da educação (níveis básico e superior), em particular. - Brasil. A partir do Consenso de Washington (1989), foram instituidas políticas neoliberais de austeridade, norteando economicamente, os Estados-nações quanto aos gastos públicos com as políticas sociais, que demarcam a maximização dos incentivos econômicos ao capital financeiro, entre outros, que orientam reformas do aparelho estatal, o avanço e a intensificação das privatizações de serviços públicos de proteção ao trabalho.

Seguindo essas orientações, a Declaração de Bolonha (1999) preconiza os caminhos e as definições sobre qual educação e para qual formação se direcionaria o mercado europeu e, consequentemente, o resto dos países capitalistas (LEWGOY; MACIEL, 2016). No Brasil, a referida legislação provoca uma avultante ruptura na implementação do plane jamento para o ensino superior, a exemplo da "a autonomia universitária, o fim dos currículos mínimos e a inclusão de uma nova modalidade de ensino superior (a distância) " (LEWGOY; MACIEL, 2016, p.26). Esta legislação suprimiu os currículos mínimos que vigoravam no ensino superior e garantiam que as grades curriculares dos cursos fossem semelhantes, em até $70 \%$, em todo o território nacional.

Em virtude da adoção hegemônica do corpo profissional e docente das Diretrizes Curriculares da ABEPSS (1996) e da aprovação de um currículo mínimo, pelo MEC que respondia às deliberações legais citadas no parágrafo precedente, foi gerado uma multiplicidade de desenhos de grades curriculares que direcionam para distintos projetos pedagógicos. Em meio as investidas das reformas na educação, do esvaziamento das diretrizes para formação acadêmica e do avanço das políticas de austeridade neoliberal, 
GOMES, V. L. B; PAIVA, S. D. T; CEZAR, K. C. M.

Formação profissional em Serviço Social e política de educação superior no âmbito das IES do PROCADAmazônia: elementos para o debate

a profissão alicerça-se em esforços de consolidação do Projeto Ético Político (PEP). através da luta coletiva.

Os primeiros anos do novo século apresentam um expressivo alargamento das instituições de Ensino à Distância (EAD), devido ao avanço tecnológico que inova apresentando uma nova metodologia de ensino. Destarte, "[...] até meados da década de 1990, os cursos à distância eram profissionalizantes ou de complementação de estudos (por correspondência e telecursos)" (LIMA, 2007, p. 145). Essa nova modalidade de ensino tem por finalidade a formação em massa de profissionais com baixo custo (LEWGOY: MACIEL, 2016). No Serviço Social, essa modalidade de ensino teve início no ano de 2006.

Uma ação significativa para o movimento privatista, no Brasil, sob o governo do. então, presidente da república. Fernando Henrique Cardoso (1995-2003), se deu por meio da promulgação da Lei no 10.260/2001 que implementou o Fundo de Financiamento ao Estudante do Ensino Superior (FIES). O programa era designado à concessão de financiamento para estudantes, regularmente, matriculado em cursos do ensino superior não gratuitos e com avaliação positiva (FERRAREZ, 2016). Em contrapartida, as Instituições Pública Federais tiveram seus recursos do Fundo Público reduzidos, drasticamente. ocasionando intenso processo de precarização do espaço universitários.

No ano de 2003, sob o primeiro governo do presidente Luís Inácio Lula da Silva, apresentou-se a proposta para reforma universitária que não veio a ser aprovada integralmente. Na prática, a reforma se estabeleceu de forma segmentada, por meio de regulamentações, pareceres e ementas. Para o Serviço Social, essa reforma fracionada implicou no aumento da oferta de cursos, promovendo, consequentemente, um crescimento do contingente profissional.

Lewgoy e Maciel (2016) afirmam que é nesse periodo que a área de Serviço Social participa, pela primeira vez, do Exame Nacional de Desempenho de Estudantes (ENADE) que, hoje, faz parte da politica de avaliação do MEC para cursos de graduação. É importante ressaltar que $\circ$ ENADE chegou a ser cogitado como um instrumento estratégico em defesa do posicionamento político da profissão. Porém, pelas inúmeras problemáticas que envolvem esse exame, a categoria abandona-o, por entende-lo como instrumento de mensuração da qualidade da formação, ao avaliar o desempenho dos discentes. A noção de qualidade preconizada por esse exame, vincula-se a lógica de 
GOMES, V. L. B; PAIVA, S. D. T; CEZAR, K. C. M.

Formação profissional em Serviço Social e política de educação superior no âmbito das IES do PROCADAmazônia: elementos para o debate

reprodução de um modelo gerencial empresarial assumido pelo Estado, na execução de sua competência reguladora, uma vez que estabelece um ranque entre as Unidades de Formação Acadêmicas (UFAS).

Toda a dinâmica de alteração e mudança na conjuntura de reforma na política de educação aqui discorrida foi acompanhada por processos de resistência da categoria profissional e suas entidades representativas. Assim, a ABEPSS publica, em 2008, um documento intitulado "Relatório final da pesquisa avaliativa da implementação das Diretrizes Curriculares do curso de Serviço Social", resultado de uma pesquisa realizada, nacionalmente, cujo o objetivo foi avaliar a implementação das Diretrizes Curriculares (1996).

A pesquisa foi realizada nas unidades de ensino filiadas à entidade e nas instituições EAD. Quanto a organização do eixo pertinente ao 'Ensino da Prática', o qual se expressa pelas Unidades de Ensino, observa-se duas principais tendências, a dizer: que o ensino teórico-prático deverá transversalizar a organização curricular, oferecendo uma sólida base para o trabalho profissional e o tratamento dispensado a respectiva prática profissional atendia parcialmente às necessidades da formação profissional, bem como a centralidade da atividade de estágio no tratamento dispendido à prática profissional na estrutura curricular. (ABEPSS, 2008)

Os resultados obtidos ao final da pesquisa possibilitaram a compreensão das estratégias adotadas pelas instituições participantes, no que concerne à implementação das diretrizes no processo de formação acadêmica e, ao mesmo tempo, colocou-se como base para a elaboração coletiva de táticas com finalidade de avançar na intensificação e no fortalecimento da consolidação da formação crítica (FERRAREZ, 2016: LEWGOY; MACIEL, 2016; COSTA, 2018).

O Conselho Federal de Serviço Social (CFESS), em relação a queda da qualidade do ensino acadêmico-profissional, encaminha aos Conselhos Regionais de Serviço Social (CRESS), o parecer jurídico de no 10/2007, estabelecendo critérios para a fiscalização de validação dos cursos de graduação, em Serviço Social, principalmente, os ofertados na modalidade EAD, assim como, "os procedimentos que deveriam ser adotados para a qualidade dos serviços prestados à sociedade pelos concluintes de tais cursos" (LEWGOY; MACIEL, 2016, p.28). 
GOMES, V. L. B; PAIVA, S. D. T; CEZAR, K. C. M.

Formação profissional em Serviço Social e política de educação superior no âmbito das IES do PROCADAmazônia: elementos para o debate

Em sintese, evidencia-se como conquistas da categoria profissional, frente ao desmonte da educação e o avanço das políticas sociais, a aprovação da Política Nacional de Estágio (2010); o documento lançado pelo CFESS (2010) intitulado "Sobre a incompatibilidade entre a graduação à distância e o Serviço Social', a fim de subsidiar o debate sobre o Estágio; e a aprovação da Lei no12.317, em 10 de agosto de 2011, que dispõe sobre a regulamentação da carga horaria de 30 horas semanais, colocando-se, enquanto um ganho importantissimo para a categoria. ${ }^{6}$

Em paralelo, operacionalizou-se o avanço da parceria público-privado, no âmbito acadêmico, com a elaboração, em 2004, do Programa Universidade para Todos (PROUNI), e promulgado por meio da medida provisória no 213 e institucionalizado pela Lei nำ11.096. de maio de 2005. O programa ofertava bolsas de estudos parciais e integrais para estudantes do curso de graduação, em instituições privadas de ensino, com ou sem fins lucrativos. Essa parceria pressupõe a dispensa legal de alguns tributos fiscais às instituições parceiras que aderirem ao programa.

Outro programa que fortalece essa parceria, é o Plano de Reestruturação e Expansão das Universidades Federais (REUNI) instituído, em 2007, por meio do Decreto no 6.096, respondendo ao disposto no Plano Nacional de Educação (PNE), de 2001/2010, o qual previa a oferta de vagas no ensino superior para, no mínimo, 30\% dos jovens brasileiros. Sobre esta iniciativa, Costa (2018, p.40) afirma que este

[...] apresenta concepções que avançam para a construção de uma Educação Superior Pública dentro de uma lógica privada, na qual as universidades se submetem a metas mercantilizadas condicionando o financiamento de custeio e de pessoal, a uma estrutura precária nas condições de trabalho dos docentes e dos técnico-administrativos em educação que atuam na construção do ensino, pesquisa e extensão nessas Universidades, e a uma escassez de financiamento para assistência estudantil que possibilite uma permanência de fato dos discentes nos cursos de graduação e pós-graduação.

Entende-se que essas modificações imprimidas nas alterações advindas dos programas e projetos de governo, não alteram a estrutura universitária ou a caráter seletivo do ensino superior - elas se movem na medida da manutenção do caráter elitista desses espaços (COSTA, 2018).- $O$ fetiche da expansão do acesso às

${ }^{6}$ Ponderamos, ainda, como um relevante ganho profissional dos anos recentes a Lei no13.935/2019 que garante o exercício profissional dos psicólogos e assistentes sociais no âmbito da política de educação básica. 
GOMES, V. L. B; PAIVA, S. D. T; CEZAR, K. C. M.

Formação profissional em Serviço Social e política de educação superior no âmbito das IES do PROCADAmazônia: elementos para o debate

universidades federais não foi acompanhado das melhorias das estruturas físicas e do corpo profissional destas instituições. Importa mencionar que, ao propor se imergir na compreensão dos meandres que circundam a formação profissional, bem como, refletir sobre seus rebatimentos no trabalho do assistente social nos espaços sócio-ocupacionais diversos, não se pode perder a perspectiva que ambos se encontram imbricados no curso do processo de acumulação do capital e dele não se apartam. Restringir o debate dessa temática, ao conhecimento, estritamente, endógeno da profissão, é desconsiderar a totalidade das relações capitalistas e, deste modo, buscar simplificações que não levaram a respostas fidedignas sobre a realidade (LEWGOY, et al., 2016).

Desta forma, procurou-se conhecer como está se dando a formação profissional do(a) assistente social, tendo por base os estudos realizados nos pós-graduações em Serviço Social que compõe o PROCAD/Amazônia que versam sobre a referida temática.

\section{A PRODUÇÃO DE CONHECIMENTO SOBRE A FORMAÇÃO PROFISSIONAL DO(A) ASSISTENTE SOCIAL NOS PPGSS'S DAS IES QUE INTEGRAM O PROCAD/Amazônia}

Estudos apresentados em eventos e publicados em periódicos e outros veículos de circulação acadêmico/profissional que versam, especificamente, sobre a temática da formação profissional, produzidos pelas entidades representativas, pelo corpo docente e discente e pela base dos assistentes sociais, alertam para a queda na qualidade da formação profissional. A descaracterização da formação profissional coloca em tensionamento as condições objetivas de materialização do Projeto Profissional, no que concerne à formação. Desta maneira, esse frágil comprometimento com uma formação crítica de qualidade, prejudica o trabalho da/o assistente social, na medida em que é necessária uma qualificação que efetive os objetivos e princípios do PEP.

Nessa esteira, embora haja um crescimento significativo no número de produções, em Serviço Social. Setubal (2007) acrescenta como um limite na produção desse conhecimento, a fragilidade na formação profissional quanto à garantia da materialização do tripé ensino, pesquisa e extensão. Pode-se destacar, nesse sentido, a expansão massiva das distintas modalidades de educação superior das quais, segundo a autora, inúmeras IES não ofertam essas três dimensões as quais expressam por meio do que as 
GOMES, V. L. B; PAIVA, S. D. T; CEZAR, K. C. M.

Formação profissional em Serviço Social e política de educação superior no âmbito das IES do PROCADAmazônia: elementos para o debate

diretrizes curriculares da ABEPSS aconselham à dinamicidade da materialização do ensino teórico-prático. Tem-se, então, uma limitação na dimensão do ensino, conforme pode ser constatado nos resultados apontados pelos trabalhos que versam sobre a formação profissional em Serviço Social e educação superior.

No âmbito da pós-graduação em Serviço Social as ingerências neoliberais para a política de educação reverberam em cortes de recursos para a ciência e tecnologia, atingindo, diretamente, o processo de pesquisas, sobretudo, na área das humanidades. Considerando os cortes nos orçamentos para o ensino superior e seus construtos, alguns Programas de Pós-Graduação - PPG's que ora foram ameaçados, organizaram-se, estrategicamente, como resistência a esse processo, em projetos de aperfeiçoamento e cooperação acadêmica, em nível nacional.

Nesse cenário, a criação dos programas de cooperação acadêmica precede de uma articulação que se dá em detrimento da expansão do Sistema Nacional de PósGraduações - SNPG e das pressões que dele emergem, bem como, da necessidade de consolidação desses programas. Vislumbrando o fortalecimento e consolidação dos PPG's, em vista de atenuar as discrepantes assimetrias regionais que incorrem em impactos significativos a manutenção destes programas e atendendo as recomendações do Plano Nacional de Pós-Graduação - PNPG foi lançado o PROCAD, nos anos 2000, em substituição ao Programa Institucional de Capacitação Docente e Técnica - PICDT.

Posteriormente, no decurso da segunda década do século XXI, há que se destacar, a austeridade fiscal e o desmonte da educação, a Emenda Constitucional no95/2016 aprovada pelo, então, governo de Michel Temer (2016-2018) que decreta o congelamento de gastos sociais federais, pelo periodo de vinte anos. Ressalta-se que a implementação desta Emenda, em especial, para a política educacional no ensino superior, inviabilizou a implementação do Plano Nacional de Educação (PNE) 2014-2024:

O decreto 9.741, publicado em março de 2019 (Brasil, 2019) contingenciou R\$ 29.582 bilhões do Orçamento Federal de 2019. Em termos orçamentários, em 2015, a Capes tinha um orçamento de R\$ 9.5 bilhões. Em 2017 menos de R\$ 5 bilhões. Em 2019, o orçamento da Capes foi de cerca de R\$ 4,2 bilhões, em 2020, caiu para R\$ 2,8 bilhões. A previsão para 2021 é de R\$ 1,9 bilhões. Nesse mesmo ano, a Capes anunciou o corte de 5.200 bolsas. No total, a agência já cortou 11.800 bolsas em 2019 (GARCIA, 2020, p. 15)

Salienta-se, nesse contexto, a recomendação da Comissão Especial de Acompanhamento do Programa Nacional de Pós-Graduação - PNPG 2011-2020 ICAPES Serviço Social em Perspectiva. Montes Claros (MG), volume 5, número 2. jul./dez. 2021. ISSN 2527-1849 
GOMES, V. L. B; PAIVA, S. D. T; CEZAR, K. C. M.

Formação profissional em Serviço Social e política de educação superior no âmbito das IES do PROCADAmazônia: elementos para o debate

apud GARCIA, 2020) que estabelece a redução substantiva do número de áreas de avaliação da agência de fomento à pesquisa CAPES. Como uma das estratégias para o enfrentamento aos desmontes neoliberais, dos PPG's, se insere o PROCAD intitulado " $A$ formação e o trabalho profissional do assistente social: aproximações e particularidades entre Amazônia e Sul do Brasil" que foi aprovado pelo PROCAD/Amazônia, Edital n-21/2018. O mencionado projeto estabelece como objetivo, a ampliação da reflexão teórico-metodológica sobre a formação e o trabalho profissional, em Serviço Social, vislumbrando elucidar as apropriações e particularidades entre dois estados da região amazônica, sendo eles Pará e Amazonas e o Rio Grande do Sul localizado, no sul do Brasil, por meio da cooperação acadêmica entre os PPG's das instituições anteriormente mencionadas. Registra-se que o referido programa de cooperação se apresenta estratégico para o fortalecimento dos programas de pós-graduação envolvidos e para a área de conhecimento do Serviço Social, sobretudo, ao levar em consideração as discrepantes realidades regionais

A cooperação proporciona, em primeiro lugar, uma rica interlocução com as produções de conhecimento dos grupos de pesquisas vinculados e a troca com os pesquisadores e coordenadores dos mesmos. Em segundo, possibilita:

[...] manter um dinâmico intercambio com base nas potencialidades dos grupos de pesquisa da UFPA e UFAM, no sentido de efetivar uma interação constante e diálogo crítico com diferentes grupos de pesquisa dentro do país, ou seja. uma intensa rede de articulação que permita a cooperação científica inter e/ou intra-regional entre grupos de pesquisa objetivando a formação e qualificação de um saber crítico, para a valorização das experiências de ensino, pesquisa e extensão no âmbito das Instituições parceiras desse projeto (PROCAD, 2018, p. 2-3)

Com base nessas considerações, realizou-se um levantamento acerca das linhas de pesquisa em vigência nas instituições de ensino superior vinculadas ao referido programa de cooperação, que os grupos de pesquisa devem seguir. Ademais, os trabalhos levantados, neste artigo, estão, necessariamente, em coerência com tais linhas de pesquisa. Realizando um breve levantamento nos sites oficiais da PUCRS, UFPA e UFAM, identificou-se as seguintes linhas de pesquisa:

Quadro 1: Apresentação das linhas de pesquisa dos PPG's que compõem o PROCADAMAZÔNIA. 
GOMES, V. L. B; PAIVA, S. D. T; CEZAR, K. C. M.

Formação profissional em Serviço Social e política de educação superior no âmbito das IES do PROCADAmazônia: elementos para o debate

Programa de

Linhas de pesquisa

Pós-graduação

\begin{tabular}{|c|l|}
\hline \multirow{4}{*}{ UFAM } & $\begin{array}{l}\text { Linha } 1 \text { - Questão social, politicas sociais, lutas sociais e formação } \\
\text { profissional. }\end{array}$ \\
\cline { 2 - 3 } & $\begin{array}{l}\text { Linha } 2 \text { - Gestão social, desenvolvimento, ambiente, direitos humanos, } \\
\text { cultura e diversidade socioambiental. }\end{array}$ \\
\hline \multirow{4}{*}{ UFPA } & Linha 1 - Serviço Social e Politicas Sociais na Amazônia \\
\cline { 2 - 3 } & Linha 2 - Serviço Social e Trabalho na Amazônia \\
\cline { 2 - 3 } & Linha 3 - Serviço Social e Direitos Humanos naAmazônia \\
\hline \multirow{5}{*}{ PUC-RS } & Linha 1 - Serviço Social, Direitos Humanos, Desigualdades e Resistências \\
\cline { 2 - 3 } & Linha 2 - Serviço Social, Ensino e Formação \\
\cline { 2 - 3 } & Linha 3 - Serviço Social, Seguridade Social e Políticas Sociais \\
\cline { 2 - 3 } & Linha 4 - Serviço Social, Trabalho e Processos Sociais \\
\hline
\end{tabular}

Fonte: Elaboração das autoras com base nas informações obtidas através dos sites oficiais das IES's vinculadas ao PROCAD/Amazônia (2018)

Nota-se, pelo quadro acima, que as principais aproximações entre as linhas de pesquisa dos PPG's que compõem o PROCAD/Amazônia (2018), são entre Políticas Sociais, Trabalho, Formação Profissional e Direitos Humanos. Neste sentido, ao realizar-se o estado da arte sobre as temáticas das dissertações e teses produzidas, nos referidos Programas de Pós-Graduação, no periodo de 2015 a 2020, verificou-se na UFAM, um total, 68 (sessenta e oito) trabalhos de pesquisas dissertativas, visto que o referido PPG, ainda, não possui curso de doutorado. Em especial, sobre o descritor "Formação Profissional em Serviço Social', os trabalhos que contemplam tal essa temática e suas múltiplas interlocuções, representam 10,29\% 107 dissertações) da produção de conhecimento da pós-graduação nessa universidade pública.

Na pós-graduação, em Serviço Social da PUC/RS, verificou-se a existência de 125 (cento e vinte e cinco) trabalhos de pesquisa entre dissertações e teses de doutorado. No intervalo que compreende os anos de recorte deste artigo, observa-se que apenas 4\% (02 teses e 03 dissertações) tem como central a formação profissional, em Serviço Social

No que se refere ao descritor "Educação Superior e Serviço Social" identificouse, as produções sobre este tema na UFAM correspondem a 2,9\% (02 dissertações) do total de dissertações e na PUCRS 1,6\% (01 tese e 01 dissertação) sobre o total de dissertações e teses produzidas até o ano de 2020. 
GOMES, V. L. B; PAIVA, S. D. T; CEZAR, K. C. M.

Formação profissional em Serviço Social e política de educação superior no âmbito das IES do PROCADAmazônia: elementos para o debate

No que tange à produção de conhecimento, na UFPA, observou-se no site do respectivo PPGSS, que o acervo de suas dissertações só está disponivel para consulta pública até o ano de 2017, assim como, não há teses publicizadas, tendo em vista que o programa de doutoramento é recente, pois, teve início, em 2016. Portanto, considerando as dissertações disponibilizadas, não foram identificadas produções acadêmicas no site do PPGSS/UFPA que versem sobre as temáticas que se pretende abordar neste estudo.

Contudo, observa-se, nas plataformas dos três PPGSS's, uma tímida produção científica sobre os temas formação profissional e educação superior, de forma a estabelecer interlocuções com o Serviço Social, como temática central de estudo. Assim, infere-se, portanto, que há, ainda, poucos estudos e pesquisas, exclusivamente, sobre educação superior, visto que as linhas de pesquisa dos mencionados programas não possuem proximidades com esses temas de pesquisas. No que concerne à formação profissional, percebe-se um quantitativo mais expressivo de trabalhos vinculados as linhas 1 e 2 dos PPG's da UFAM e PUC-RS respectivamente.

Sendo assim, foram identificadas as seguintes teses e dissertações sobre as temáticas: educação superior e formação profissional, em Serviço Social, no periodo pesquisado: na temática da "formação profissional em Serviço Social", identificou-se a dissertação de mestrado de Hoepner (2017), intitulada 'A viagem de volta': a formação profissional em Serviço Social no Estado do Rio Grande do Sul", a qual analisa a realidade da formação profissional, no respectivo estado. Para tal, o autor realizou entrevistas com coordenadores de curso de Serviço Social, docentes e discentes de distintas IES? em todas as mesorregiões. O estudo revelou que, em um periodo de aproximadamente sessenta anos, a formação profissional de assistentes sociais gaúchos foi, prioritariamente, em instituições de natureza privada, em decorrência do panorama nacional de expansão dessa modalidade de ensino, conforme foi tratado no item precedente deste artigo.

Evidenciou-se que, embora, hegemonicamente os coordenadores das instituições participantes da pesquisa afirmem que as estruturas dos projetos pedagógicos dos seus

\footnotetext{
7 As instituições participantes da pesquisa são a Pontifícia Universidade Católica do Rio Grande do Sul (PUCRS), Universidade Federal do Pampa (UNIPAMPA), Centro Universitário Franciscano (UNIFRA), Universidade de Passo Fundo (UPF), Universidade Católica de Pelotas (UCPel), Universidade de Santa Cruz do Sul (UNISC) e Universidade de Caxias do Sul (UCS).
}

Serviço Social em Perspectiva, Montes Claros (MG), volume 5, número 2. jul./dez. 2021. ISSN 2527-1849 
GOMES, V. L. B; PAIVA, S. D. T; CEZAR, K. C. M.

Formação profissional em Serviço Social e política de educação superior no âmbito das IES do PROCADAmazônia: elementos para o debate

cursos sejam norteadas pelo que preconizam as Diretrizes Curriculares da ABEPSS (1996), as instituições dialogam, parcialmente, ou de modo fragmentado com tais diretrizes. Nesse sentido, Hoepner (2017) sinaliza que em alguns dos currículos analisados, identificaram-se traços das estruturas curriculares precedentes a proposta da ABEPSS (1996). Segundo o autor, esse fenômeno contribui para fragilizar as conquistas da profissão materializadas nas atuais Diretrizes Curriculares (1996). O autor alerta para a necessidade de aprofundar, em pesquisas posteriores, a compreensão dos docentes sobre as Diretrizes Curriculares de 1996.

Além desta dissertação de mestrado sobre formação profissional em Serviço Social foi identificado outra no PPGSS/UFAM. Trata-se do trabalho de pesquisa elaborado por Lima (2017) intitulado Formação profissional em debate: um estudo dos projetos pedagógicos do curso de Serviço Social em Manaus, a partir das novas Diretrizes Curriculares de 1996. Em seus resultados, Lima (2017) ressalta a fidedignidade dos projetos pedagógicos das faculdades para com as diretrizes norteadoras da formação profissional ABEPSS/MEC, frisando a proximidade, em específico, dos currículos pedagógicos com as diretrizes da ABEPSS (1996).

No que concerne o acesso ao tripé ensino, pesquisa e extensão, a autora referese que a UFAM dispõe, em sua estrutura curricular, de uma dinamicidade e flexibilidade ao considerar a oferta de diversas atividades extracurriculares ${ }^{8}$; há maior incentivo a inserção dos discentes de graduação nos projetos/programas de pesquisa e extensão desenvolvidos pela instituição acadêmica. Em paralelo, a FSDB

\begin{abstract}
dentro de suas limitações procura trabalhar a pesquisa e a extensão, entretanto por ser de natureza privada, não há incentivo e nem recursos efetivos para a mesma, como fomentado pela UFAM, porque a pesquisa e a extensão exigem disponibilidade de professor, ou seja, dedicação exclusiva, o que não existe nas instituições privadas, uma vez que o regime de contratação dos professores é horista (LIMA, 2017, p. 117, grifos nossos).
\end{abstract}

A propósito, Lima (2017) afirmou que, embora haja tal adversidade, a referida faculdade preconiza em sua proposta pedagógica o desenvolvimento de atividades curriculares, extracurriculares e complementares, em consonância com as diretrizes da ABEPSS (1996). Em ambas as instituições, verificou-se a coerência quanto a formação e

\footnotetext{
8 Seminário, encontros, oficinas, estágio supervisionado, apresentação de trabalhos, entre outros (Lima, 2017)
} 
GOMES, V. L. B; PAIVA, S. D. T; CEZAR, K. C. M.

Formação profissional em Serviço Social e política de educação superior no âmbito das IES do PROCADAmazônia: elementos para o debate

capacitação teórico-metodológico e ético-político dos discentes, imprescindivel para o exercício da dimensão técnico-operativo.

Ao que concerne aos trabalhos encontrados sobre "educação superior e Serviço social" na produção da UFAM, destaca-se o trabalho de PAIVA (2016), intitulado "As transformações do trabalho docente na Universidade Federal do Amazonas: da produção ao produtivismo na pós-graduação". O estudo em questão trata das transformações ocorridas no trabalho docente na pós-graduação da Universidade Federal do Amazonas (UFAM) e a relação entre a produção científica e o produtivismo acadêmico. Partindo de uma pesquisa de campo com 10 (dez) docentes dos Programas de Pós-Graduação dos cursos das áreas Interdisciplinar ${ }^{9}$. Ciências Sociais Aplicadas ${ }^{10}$ e Ciências Humanas ${ }^{11}$ da referida IES, a autora constatou que se vivencia uma sobrecarga de trabalho docente, mediante as crescentes exigências de produção na pós-graduação, nas quais a quantidade sobrepõe-se à qualidade científica.

Deste modo, em decorrência do contexto neoliberal e da retração do Estado para as políticas sociais, em particular, a educação, foram instituidos cortes orçamentários para a mencionada política, os quais obrigam o lals docentes a concorrer em editais de financiamento para suas pesquisas; além disso, estão submetido (a)s a precárias condições de trabalho, bem como, a extensas jornadas de trabalho no contexto familiar.

No que tange ao resultado da pesquisa na PUCRS, evidencia-se a dissertação de LAMPERT (2020), sob o título "Transformações societárias em contexto pós-golpe de 2016 e suas implicações para formação presencial em Serviço Social no Rio Grande do Sul". O mencionado trabalho versa sobre como as transformações societárias e as configurações da educação superior no Brasil, marcadamente, a partir do golpe de 2016 . reverberam nos cursos presenciais de Serviço Social no estado do Rio Grande do Sul.

Os resultados obtidos com a referida pesquisa revelam que a tendência a mercantilização do ensino superior se intensificou, no contexto supracitado, principalmente, ao considerar a EC 95/2016, conforme mencionado, anteriormente. Ao que se refere aos rebatimentos desse processo para os cursos de Serviço Social, o

\footnotetext{
9 Sociedade e Cultura na Amazônia.

10 Ciências da Comunicação e Serviço Social.

11 Antropologia, Educação, Geografia, História, Letras, Psicologia e Sociologia.
}

Serviço Social em Perspectiva, Montes Claros (MG), volume 5, número 2. jul./dez. 2021. ISSN 2527-1849 
GOMES, V. L. B; PAIVA, S. D. T; CEZAR, K. C. M.

Formação profissional em Serviço Social e politica de educação superior no âmbito das IES do PROCADAmazônia: elementos para o debate

autor aponta que há uma tendência dos cursos de faculdades privadas presenciais, passarem a ser ofertados, totalmente, na modalidade a distância no estado pesquisado.

Dessarte, revelou-se que as influências mercantilistas expressas na formação EAD. tensionam e disputam espaço com as IES presenciais, provocando um movimento de reestruturação e reorganização de projetos pedagógicos, a partir das ideias neoliberais. Neste contexto, há uma derruição da formação crítica, devido a lógica de concorrência entre as $\mathbb{E}$, sob o viés da maximização dos lucros e precárias condições de ensino, os quais reverberam, ainda, no trabalho dolal assistente social que atua como docente, uma vez que há uma redução dos gastos, aumentando a polivalência, intensificação e sobrecarga de trabalho em condições precárias.

Ressalta-se que as produções acadêmicas pesquisadas apontam as determinações gerais dos respectivos objetos de estudo, tais como: as transformações societárias, a nova morfologia do mundo do trabalho, as inflexões da crise do capitalismo contemporâneo e as diretrizes neoliberais para a politica de educação, em particular, do ensino superior. Outro ponto de relevância diz respeito ao percurso teóricometodológico orientador dos processos de pesquisa citados por estes trabalhos, o qual permitiu a análise do real, a partir das mediações entre singularidade, particularidade e universalidade por meio do método do materialismo histórico-dialético reafirmando, assim, a orientação hegemônica do Serviço Social pelo método em Marx.

Continuando, as conclusões apontadas nas quatro pesquisas expostas sinalizam para a tendência de privatização, intensificadas ao longo dos anos, da educação superior, balizadas pela expansão do EAD, do aligeiramento e precarização da formação profissional em Serviço Social que incorrem, entre outros, na graduação de profissionais alinhados a perspectivas de práticas formais-abstratas que reproduzem as ideias neoliberais nos diferentes espaços sócio-ocupacionais.

\section{CONSIDERAÇÕES FINAIS}

A elaboração deste artigo nos permitiu inferir, a partiras análises efetuadas nas teses e dissertação dos PPGS's das IES's que integram o PROCAD-Amazônia, que o processo de mercantilização do ensino superior, no Brasil, vem se intensificando, o que 
GOMES, V. L. B; PAIVA, S. D. T; CEZAR, K. C. M.

Formação profissional em Serviço Social e política de educação superior no âmbito das IES do PROCADAmazônia: elementos para o debate

conduz à fragilização das conquistas da profissão materializadas nas atuais Diretrizes Curriculares (1996), sobretudo, a partir da EC 95/2016, que congela os gastos sociais por 20 anos.

Um dos rebatimentos dessa realidade para os cursos de Serviço Social, é que há uma tendência dos cursos de faculdades privadas presenciais, passarem a ser ofertados, majoritariamente, na modalidade a distância, pois, na totalidade das IES privadas presenciais observa-se precários vínculos empregatícios, com contratos de trabalho na modalidade "horista", inviabilizando a dedicação exclusiva dos docentes às atividades de pesquisa e extensão universitária (PONTES et. al, 2020).

As inflexões deste processo repercutem, não apenas para olals discentes, mas também, para os docentes assistentes sociais e das demais áreas de conhecimentos, os quais são submetidos, entre outros: as longas jornadas de trabalho que se estendem para os seus lares; a pressão por produtividade científica; falta de condições de trabalho adequadas no cumprimento de suas atividades, principalmente, em decorrência do corte de recursos financeiros.

\section{REFERÊNCIAS}

ABEPSS. Diretrizes gerais para o curso de Serviço Social. Rio de Janeiro, 1996.

ABEPSS. Relatório final da pesquisa avaliativa da implementação das Diretrizes Curriculares do curso de Serviço Social. Brasilia, 2008.

ABRAMIDES, B. O projeto ético-político do Serviço Social Brasileiro: ruptura com o conservadorismo. São Paulo: Cortez, 2019.

BRAVO, Maria Inês Souza, RAIZER, Eugênia Célia, LEMOS, Esther Luíza de Souza, ELPÍDIO, Maria Helena. O protagonismo da ABESS/ABEPSS na virada da formação profissional em Serviço Social. In: OLIVEIRA E SILVA, Maria Liduína de (org.). Congresso da Virada e o Serviço Social hoje: Reação conservadora, novas tensões e resistências. São Paulo: Cortez, 2019.

ABREU, M. A formação profissional em Serviço Social e a mediação da Associação Brasileira de Ensino e Pesquisa em Serviço Social (ABEPSS): as diretrizes curriculares/1996 em relação à perspectiva emancipatória no âmbito do avanço do conservadorismo. In: SILVA, M. (org). Serviço Social no Brasil: história de resistência e de ruptura com o conservadorismo. São Paulo: Cortez, 2016. p. 235-264.

Conselho Federal de Serviço Social - CFESS. Sobre a impossibilidade entre graduação à distância e Serviço Social. Vol. 02 Brasilia. 2014. 
GOMES, V. L. B; PAIVA, S. D. T; CEZAR, K. C. M.

Formação profissional em Serviço Social e politica de educação superior no âmbito das IES do PROCADAmazônia: elementos para o debate

COSTA, Fabiana. As particularidades do Ensino Superior brasileiro nos marcos do capitalismo dependente. Temporalis, Brasilia (DF), ano 18, n. 35, jan./jun., 2018.

FERRAREZ, C. Mercantilização da educação superior brasileira e a formação profissional do Serviço Social. Temporalis, Brasília (DF), ano 16, no31, jan./ jun. 2016.

GARCIA, M. L. T. Prefácio. In: CUNHA, M. G. N.; PRATES, J. C.; ANDRADE, R. F. C. de; BORDIN, E. B. PROCAD AMAZÔNIA: formação e trabalho do assistente social no norte e sul do Brasil. Manaus: EDUA; São Paulo: Alexa Cultural, 2020

HOEPNER, C. M. "A viagem de volta": a formação profissional em Serviço Social no Estado do Rio Grande do Sul. Dissertação (Mestrado em Serviço Social) - Programa de PósGraduação em Serviço Social. Pontífice Universidade Católica do Rio Grande do Sul, Porto Alegre, 2017.

IAMAMOTO. M. O Serviço Social na contemporaneidade: trabalho e formação profissional. São Paulo: Cortez, 2015

IAMAMOTO, M.; CARVALHO, R. Relações Sociais e Serviço Social no Brasil. São Paulo: Cortez, 2014.

IAMAMOTO, Marilda. O Serviço Social na contemporaneidade: trabalho e formação profissional. Cortez, 2005.

LEWGOY, A. et al. Formação profissional em serviço social: de que se trata? Temporalis. Brasilia, n. 31, jan./jun., 2016

LEWGOY, A.: MACIEL, A. O projeto de formação em Serviço Social: análise da sua trajetória histórica no periodo 1996 a 2016. Temporalis: Brasília, n. 32. jul./dez., 2016.

LIMA, N. G. H. Formação profissional em debate: um estudo dos projetos pedagógicos do curso de Serviço Social em Manaus a partir das novas Diretrizes Curriculares de 1996. Dissertação (Mestrado em Serviço Social) - Programa de Pós-Graduação em Serviço Social e Sustentabilidade. Universidade Federal do Amazonas, Manaus.

MACIEL, A. Universidade em crise: uma travessia necessária para a formação em serviço social. Tese (Doutorado em Serviço Social) - Pontífice Universidade Católica, Porto Alegre, 2006. $220 \mathrm{f}$.

MARX, K.: ENGELS, F. Crítica da educação e do ensino. Campinas, São Paulo: Navegando. 2011.

MEC - Ministério da Educação. Disponível em: https://www.gov.br/mec/pt-br Acesso em: 10 fev. 2020.

NETTO, J. P. Capitalismo monopolista e Serviço Social. 8o edição. São Paulo: Cortez, 2011. 
GOMES, V. L. B; PAIVA, S. D. T; CEZAR, K. C. M.

Formação profissional em Serviço Social e política de educação superior no âmbito das IES do PROCADAmazônia: elementos para o debate

NETTO, J. P. Ditadura e Serviço Social: uma análise do Serviço Social no Brasil pós-64. 160 edição. São Paulo: Cortez, 2011.

PONTES, et. al. As condições de vida e trabalho das/os Assistentes sociais na região metropolitana de Belém: aproximações reflexivas. In: CUNHA, M. G. N.; PRATES, J. C.; ANDRADE, R. F. C. de; BORDIN, E. B. PROCAD AMAZÔNIA: formação e trabalho do assistente social no norte e sul do Brasil. Manaus: EDUA; São Paulo: Alexa Cultural, 2020. p. 249-271.

SAVIANI, D. Trabalho e Educação: fundamentos ontológicos e históricos. Revista Brasileira de Educação, Rio de Janeiro, vol. 12, no 34, 152-165, jan./abril., 2007.

LAMPERT, Michael da Costa. Transformações societárias em contexto pós-golpe de 2016 e suas implicações para formação presencial em serviço social no rio grande do sul. 2020. 156 p. Dissertação de mestrado - Programa de Pós-graduação em Serviço Social, PUCRS.

PAIVA, Janaina Zildéia da Silva. As transformações do trabalho docente na Universidade Federal do Amazonas: da produção ao produtivismo na pós-graduação / Janaína Zildéia da Silva Paiva. - 2016. 167 f. Dissertação de mestrado - Universidade Federal do Amazonas.

SETUBAL, Aglair Alencar. Desafios à pesquisa no Serviço Social: da formação acadêmica à prática profissional. Revista Katálysis, v. 10, n. SPE, p. 64-72, 2007.

SIMIONATTO, Ivete; NEGRI, Fabiana. Gramsci e a produção do conhecimento no Serviço Social brasileiro. Revista Katálysis, v. 20, n. 1, p. 13-21, 2017. 